\title{
Pentecostalidad y procesos de identificación política disruptiva. Un estudio de caso en Argentina
}

\author{
Pentecostalidade e processos de identificação política disruptiva. \\ Um estudo de caso na Argentina
}

Nicolas Panotto *

\begin{abstract}
Resumen
El artículo plantea la hipótesis de que los elementos constitutivos del pentecostalismo (en su dimensión identitaria, ritual, institucional, discursiva y teológica) presentan la suficiente heterogeneidad, maleabilidad y dinámica para habilitar reapropiaciones y modos de identificación diversos, desde una dimensión crítica e intrínsecamente política, tanto a nivel individual como colectivo. Para el presente estudio, analizaremos el caso de una comunidad pentecostal en la ciudad de Buenos Aires, el Centro Cristiano Nueva Vida (CCNV), con el propósito de indagar cómo las dinámicas institucionales, las performances de subjetividad pentecostal y la resignificación de discursos teológicos, sirven a la promoción y construcción de posiciones políticas alternativas. Para ello, nos concentraremos en dos temas centrales. Primero, en cómo el CCNV comprende su identidad pentecostal desde una dinámica disruptiva, tanto en su dimensión religiosa como socio-comunitaria. Y segundo, la reapropiación de elementos discursivos -especialmente dentro de la matriz teológica evangélico/pentecostal- que operan en el CCVN como instancias de posibilitan resignificaciones en términos de prácticas y sentidos socio-políticos.
\end{abstract}

Palabras clave: Identidad. Pentecostalidad. Política. Espíritu. Militancia.

\begin{abstract}
The hypothesizes this article suggest that the constitutive elements of Pentecostalism (in its identity, ritual, institutional, discursive and theological dimensions) are sufficiently heterogeneous, malleable and dynamic to enable reappropriations and diverse modes of identification, from a critical and intrinsically political dimension, both at the individual and collective levels. For the present study, we will analyze the case of a Pentecostal community in the city of Buenos Aires, the Centro Cristiano Nueva Vida (CCNV), with the purpose of investigating how institutional dynamics, the performances of Pentecostal subjectivity and the resignification of theological discourses, serve to the promotion and construction of alternative political positions. To this end, we will focus on two central themes. First, how the CCNV understands its Pentecostal identity from a disruptive dynamic, both in its religious and sociocommunitarian dimensions. And second, the reappropriation of discursive elements -especially within the Evangelical/Pentecostal theological matrix- that operate in the CCNV as instances that enable resignifications in terms of socio-political practices and meanings.
\end{abstract}

Keywords: Identity. Pentecostalism. Politics. Spirit. Militancy. 


\section{Introducción}

Hay dos intereses, formulados a modo de hipótesis, que motivan este trabajo. Primero, el fenómeno de la heterogeneidad de identificaciones políticas hacia dentro del campo evangélico. Frente a la imposibilidad de establecer un posicionamiento político homogéneo dentro de este espectro religioso, nos preguntamos: ¿qué es lo que habilita tal pluralidad? ¿Existen elementos constitutivos que gatillan dichos procesos? Segundo, la relación entre evangélicos y política no debe ser representada como dos campos con fronteras fijas que se enlazan a través de un puente que los une de manera contingente frente a alguna coyuntura particular. Hay que hablar, más bien, que lo político es una dimensión inscrita en las propias prácticas, rituales e imaginarios religiosos dentro del campo evangélico.

En otro trabajo (PANOTTO, 2016) proponemos tres maneras de observar la relación entre lo evangélico y lo político, con sus respectivos marcos teóricos, metodológicos y epistemológicos. La primera es la institucionalista, donde la dinámica se concibe en términos de influencia de competencias, es decir, desde la medida en que cada campo incide en el otro a partir de los tipos de relación que constituyen a nivel de estructura institucional. Estos abordajes tienden a medir la incidencia de lo religioso en el campo político mayoritariamente desde una mirada cuantitativa, como por ejemplo midiendo el número de candidatos referentes a la comunidad religiosa que ingresan a filas partidarias, el tipo de influjo que logran en procesos dentro del campo político burocrático o estableciendo el nivel de visibilidad en el espacio público a través del caudal electoral.

Otro de los modos de forjar esta relación es la pragmática, la cual tiene mucha relación con la anterior - ya que su marco de mediación es el campo de la política institucional y formal-, aunque se orienta más específicamente en las formas en que cada agente utiliza al otro a favor de sus intereses particulares. En este caso, los estudios se focalizan en las estrategias de articulación que cada sujeto opera con el objetivo de vincularse con el otro, como por ejemplo la acción de grupos políticos en iglesias con la intención de ganar posibles 
electores o el análisis sobre el énfasis que otorgan algunos grupos religiosos al compromiso político como un modo de "ganar el mundo" o de "moralizar la política” (CARBONELLI, 2009), de alcanzar visibilidad pública o hasta beneficios sociales y económicos.

El tercer abordaje es el simbólico-discursivo. En este caso las fronteras de la relación se hacen mucho más porosas y difusas. Podemos ver espacios políticos que utilizan discursos religiosos para describir sus programas, narrativas políticas que son utilizadas por comunidades religiosas desde lecturas teológicas, o discursos políticos que alcanzan un lugar relevante dentro de ciertas cosmovisiones religiosas. En otros términos, los vínculos se manifiestan en la intersección de dos campos cuyas delimitaciones por momentos no son posibles de distinguir con claridad (ALGRANTI, 2007).

Todos estos abordajes son válidos según el objetivo de la investigación y los tipos de agentes en juego dentro del proceso. De todos modos, lo que caracteriza a todos ellos es que dan cuenta de la lógica intersticial que reside en el vínculo entre lo religioso y lo político; es decir, que conciben una relación entre campos que entran en juego, donde cada agente es definido como un objeto con fronteras identitarias porosas y lábiles. En este sentido, hablar de relación no significa sólo la identificación de lineamientos que unifican objetos suturados sino de un proceso de deconstrucción del estatus ontológico de cada cuerpo identitario a partir del encuentro con el otro.

En el caso de la investigación que nos compete, nos concentraremos en el análisis simbólico-discursivo, con el objetivo de identificar, clasificar y cruzar las matrices que se entrelazan a la hora de delimitar un terreno y un conjunto de procesos de identificación que distan de ser homogéneos; más bien, dan cuenta de la diversidad de vinculaciones entre lo religioso y lo político a partir de una identificación particular, en este caso en la iglesia pentecostal Centro Cristiano Nueva Vida (CCNV), una comunidad eclesial cuya sede principal se encuentra en Buenos Aires pero opera en todo el país, e inclusive en todo el Cono Sur. 
El CCNV es una iglesia que nació bajo el seno de la Unión de las Asambleas de Dios en el año 1982, en Parque Patricios, un barrio de clase media en la Ciudad de Buenos Aires. Comenzó su trabajo como casi todas las iglesias pentecostales de su tiempo: con pequeños grupos en casa y "campañas evangelísticas". El CCNV tuvo diversos procesos y etapas. Los '8o fue el tiempo de afianzamiento y construcción institucional, mientras la década de los '9o representó un período de crecimiento exponencial, extensión por todo el país y desarrollo de proyectos de incidencia en diversos sectores populares de la ciudad. Lo que marcó un nuevo período fue la crisis del 2001 en Argentina, que catapultó la imagen pública de esta iglesia -especialmente la figura de su pastor principal, Guillermo Prein-, donde el CCNV se transformó en un importante referente político, tanto por la distancia crítica que estableció frente a otros referentes evangélicos en el país como por los vínculos que comienza a tejer más formalmente con el peronismo del momento (desde el gobierno de Eduardo Duhalde en el 2002, pero principalmente con Néstor Kirchner a partir de 2003) y diversos proyectos de incidencia que desarrollarán y alcanzarán notable visibilización.

El trabajo etnográfico realizado en el CCNV se desarrolló entre los años 2012 y 2018, a través de observación participante en las principales reuniones litúrgicas y en algunos de los ministerios de interés para los objetivos de la investigación, así como a través de entrevistas a referentes del liderazgo eclesial y del análisis documental de escritos producidos por el pastor principal. Teniendo en cuenta lo antedicho, y partir del estudio realizado, lo que intentamos confirmar como hipótesis lo siguiente: frente al imaginario generalizado de que el pentecostalismo es una fuerza intrínsecamente conservadora ante los procesos sociales y políticos progresistas e inclusivos, sostenemos que la dinámica, labilidad y posibles reapropiaciones de sus elementos constitutivos como identidad religiosa operan de forma movible, permitiendo ser resignificados desde distintas cosmovisiones, experiencias, demandas y marcos ideológicos, constituyendo así un campo de operación y desplazamiento político con derivaciones heterogéneas, muchas de ellas críticas con una agenda conservadora. 


\title{
1 Resignificación de la pentecostalidad y la incidencia pública
}

\subsection{Sobre la dimensión disruptiva de "lo pentecostal"}

La constitución del pentecostalismo es disruptiva desde su origen. Disruptiva con respecto al tradicionalismo protestante, al formalismo católico romano, a los procesos de marginalización de sectores vulnerables, y en relación a su articulación con ritualidades y experiencias religiosas periféricas. En el caso del CCNV, esta dimensión se inscribe en varios elementos, que van desde su estructura institucional hasta las configuraciones rituales y discursivas que asume, pero principalmente en la forma en que configura su pentecostalidad. En este sentido, todos los elementos característicos que promueve la espiritualidad pentecostal -el lugar de la experiencia personal, las emociones, los milagros, la sanidad del cuerpo, las manifestaciones extraordinarias- son entendidas, no desde un ascetismo religioso -como se tiende a pensar- sino desde otras claves interpretativas y vivenciales sobre lo público y la dimensión social de la fe, la espiritualidad y la iglesia. Guillermo Prein (2008) ofrece la siguiente definición de lo que son los “pentecostal-es":

\begin{abstract}
Pentecostal-es la comunidad de gente que, en todos los continentes, vive y desarrolla una fe que produce milagros constantes y comprobados. Pentecostal-es la salida de la miseria. Todavía, Dios multiplica panes y peces, da ideas y te enseña dónde tirar las redes para que tu productividad se multiplique de o a 153 peces grandes: un $300 \%$. Pentecostal-es el mensaje que sacó a Argentina de la crisis de 2001 con una profecía clara que fue publicada en el libro Dios y la Patria lo demandan. Reconocido por economistas y políticos, Argentina se levantó por un milagro. Pentecostal-es el poder que libera al hombre de las ataduras de vicios y cadenas, que lo reencausa en una nueva dimensión y lo catapulta a una nueva vida. Pentecostales la esperanza y la seguridad de que nuestra tierra se levanta en un nuevo tiempo que no será abortado. Si los dirigentes no cumplen su función con honestidad, serán reemplazados como lo fueron sus predecesores. Pentecostal-es el poder que, por medio de los milagros, logra cualquier objetivo. Pentecostal-es la visión que se atreve a desafiar al futuro cruel que nos presentan los agoreros disfrazados de tecnócratas. Pentecostal-es el futuro del desarrollo de las misiones en todo el mundo, ya que el cambio de manos de las riquezas que salen de los impíos hacia las manos del pueblo, serán la base de la financiación de las misiones que producirán el último y gran avivamiento. (PREIN, 2008).
\end{abstract}

Esta cita da cuenta de la singular retórica de Prein, pastor principal del CCNV, elemento que destaca la forma en que se construyen sus argumentos teológicos, modalidad que influye, además, en diversos niveles dentro de la 
cosmovisión de la propia comunidad. Su retórica representa una matriz donde se entremezclan discurso religioso (más específicamente pentecostal) y conceptos sociopolíticos, en un entretejido donde ambos campos se solapan y entremezclan, impidiendo muchas veces identificar dónde termina uno y comienza otro.

Podemos destacar dos elementos centrales de esta modalidad. Primero, el potencial articulador que posee este tipo de uso del lenguaje religioso en tanto significante vacío (LACLAU, 1996) Términos como “fe”, "Dios”, "milagro", entre otros, poseen la capacidad de relacionar diferentes campos del sentido, en este caso sociopolíticos. En otras palabras, tienen una función metonímica (ALGRANTI, 2009) que permite un intercambio entre campos de significación (en este caso, religión, iglesia, sociedad y política), dando lugar a la construcción de una matriz significante que no sólo vincula cada término entre sí sino, especialmente, los hace co-dependientes, al decodificar las fronteras de sentido aplicadas a los discursos religiosos y teológicos.

Si pasamos a analizar elementos aún más específicos dentro de la cosmovisión del liderazgo del CCNV, vemos un uso particular de diversos conceptos y prácticas, como las profecías, los milagros y la conversión. Estos elementos dentro del universo simbólico pentecostal poseen una eficacia particular para redefinir experiencias de crisis personales y contextuales (MÍGUEZ, 2001) De aquí, las apelaciones a los milagros, la multiplicación, la provisión o las profecías, se transforman en marcos de acción y relectura de los procesos sociales, empoderando la agencia del creyente a partir de su propia fe (PANOTTO, 2014).

Esto lo vemos, por ejemplo, en el uso que hace el CCNV sobre las "palabras proféticas”. La iglesia acostumbra a establecer su agenda de trabajo anual a partir de una "palabra" divina (profecía), es decir, un mensaje que Dios otorga directamente a la comunidad, transmitida a través del pastor. A continuación, podremos ver algunas secciones de la profecía recibida para el año 2014: 


\section{AVANZÁ CON FE COMBATIVA}

Muros que caen al paso del pueblo, rameras transformadas en heroínas, débiles campesinos vencedores de ejércitos inmensos, niños transformados en líderes profetas-reformadores.

La FE COMBATIVA no conoce de resignación, sabedora de que todo puede y debe cambiar. Con ella te arropa JESÚS, cuando te abraza y te introduce en la IGLESIA DEFINIDA y REVOLUCIONARIA, un pueblo transformador de la realidad individual y colectiva, pues además de su poder milagroso, te impregna con amor por el prójimo y te extirpa el egoísmo del alma.

\section{MILAGROS Y VALENTÍA}

Animémonos a tomar en las manos esas serpientes venenosas que tanto daño han hecho.

Debemos saber que no está todo escrito, aún hay mucho por redactar, la historia recién comienza. Llegar a los capítulos que narran las hazañas y milagros en tu vida, de eso se trata.

Revolución de FE que pone en fuga demonios, usando un nuevo lenguaje repleto de amor, justicia y paz, que se habla, se canta y se lleva a los hechos más cotidianos sanando toda herida y enfermedad del alma y del cuerpo...

Determinados, veremos cambiar los tiempos. Caminando por un sendero de justicia, la paga llegará a las manos de quienes se levanten con una nueva identidad; el ADN de la IGLESIA REVOLUCIONARIA: no conformarse con la realidad, sino que con amor, fe y perseverancia, cambiarla en gloria. Justicia tantas veces negada al pueblo, llega produciendo gozo a hombres, mujeres y niños. La familia recibirá el bien de su labor. (PREIN, 2013). ${ }^{1}$

La apelación a las profecías o "palabras" (de Dios), sea para un individuo o para toda comunidad, es una práctica común dentro del pentecostalismo. El uso de la profecía se inscribe en una discusión histórica dentro del campo evangélico, entre aquellas corrientes que se oponen a cualquier palabra profética en el presente (ya que todo fue dicho en la Biblia; solo nos queda interpretarla), quienes apelan a la necesidad de corroborar toda profecía a través del texto bíblico para no entrar en contradicción con lo que ella dice como palabra revelada final, o aquellos (en su mayoría pentecostales) que aceptan la práctica profética en la actualidad como un elemento más de la espiritualidad.

En el caso del CCNV, la profecía es utilizada como dispositivo articulador de varios elementos (tanto institucionales como discursivos), aunque el lugar que posee dentro de las prácticas eclesiales - especialmente del liderazgo - le da una capacidad significante particular. Esto se relaciona con lo desarrollado por Rafael Falco (2010) sobre la relación entre la reinterpretación de sistemas

1 Las "profecías" han cambiado con el paso de los años, pero decidimos mencionar la de 2014, que corresponde al período de investigación. 
míticos y el carisma (comprendido como poder circulante, no sólo como investidura unipersonal). También remite a lo desarrollado por Bourdieu (2002) sobre el hecho de que en un discurso (institucional) no sólo las palabras tienen poder sino también la propia investidura que posee el "medio" - persona o autoridad- que lo enuncia (PANOTTO, 2020). De aquí, el tipo de articulación de esta profecía establece una condición ontológica singular debido a su función dentro de la cosmovisión pentecostal y por el "poder” que emana su evocación por parte del líder de la iglesia. En un intercambio de correos electrónicos, Guillermo Prein indica lo siguiente con respecto al uso de profecías:

La Palabra Profética de cada quinquenio, año y trimestre, no difiere de lo que es el leccionario metodista en su forma genérica. Es más abierto por ser trimestral por eso cada uno de los que ministran pueden tomar una parte u otra, en cambio el leccionario tiene un texto para cada día, el cual es mencionado en los cultos. Además, la construcción de esta Palabra no solo involucra a una persona, sino que quienes reciben algo y lo comparten, se suma, ya como el cuerpo central de la misma o como confirmación, la cual es tanto o más importante que la primaria. Decimos que es profética, porque lo es para nosotros en forma particular y nos dirige como brújula, pero también porque su cumplimiento a través de los años indica que es así. Ejemplo el $3 \mathrm{er}$ trimestre de 2016, recibida en noviembre 2015 y proclamada el 15 de diciembre de 2015: Zac 14.21, NUEVAS FORMAS, habla de las ollas. Como señal indiscutible al comienzo del 3er trimestre, en junio 2016, ollas populares y cacerolas. Eso como señal. Luego nosotros profundizamos en el contenido de la misma: se acaba el altar único, todos somos ollas y serviremos a todos quienes quieran venir a tomar de nosotros que limpiamos nuestra olla y la llenamos de frutos y dones del ESP, poniendo fin a los mercaderes que están dentro del templo del ESP, es decir de nosotros. Allí hicimos una relectura del Génesis y sobre todo de la vida de Jacob y su conversión en Israel. (PREIN, 2016).

Los conceptos de "fe" y "milagros" también son utilizados de un modo particular en el CCNV, al menos comparando con otras apropiaciones dentro del campo pentecostal. También representan instancias disruptivas en la vivencia cotidiana del creyente, aunque en el caso del Centro pretenden ser prácticas de resignificación más amplias, es decir, proyectar un tipo de movilización que involucra tanto a la iglesia como al barrio y la ciudad. Por ejemplo, la dimensión económica de algunas de las intervenciones consideradas "milagrosas" -por ejemplo, la oración por trabajo, por mejora en la condición material, por el avance de proyectos personales, etc.- se diferencia de la denominada "teología de la prosperidad" y su modo de comprender la provisión económica de Dios (SEMÁN, 2001); teología -de hecho- fuertemente cuestionada dentro del CCNV. 
En el caso del Centro, las transformaciones que se dan en el área económica, tanto en individuos como en familias, negocios o emprendimientos, se ubican dentro de una lectura sociopolítica crítica. No son comprendidas simplemente como intervenciones divinas extraordinarias en el sentido tradicional sino, más bien, desde una mirada co-participativa de la misma comunidad. Por ejemplo, los esfuerzos de trabajo comunitario de la iglesia son ubicados como un modo a través del cual esas transformaciones son también utilizadas por Dios. "Lo milagroso", más que un hecho portentoso, se presenta a través de la obtención de un nuevo trabajo, el mejoramiento de la condición financiera de una persona o los resultados del trabajo de incidencia social de la iglesia; es decir, una instancia de transformación radical tanto individual como familiar y grupal.

Uno de los ministerios eclesiales más relevantes para la indagación de esta dimensión disruptiva de la pentecostalidad en el CCNV es el grupo denominado Liberando Argentina con Trabajo y Educación (LATE) Este ministerio reúne a hombres y mujeres de la iglesia comprometidos con algún tipo de activismo político, sea partidario (en sus varios espectros, que van desde la derecha hasta la izquierda) o en movimientos sociales. LATE comenzó como un espacio de debate político hacia dentro de la iglesia, que derivó en el desarrollo de proyectos de incidencia, tales como la apertura de una Mutual (centro que articula esfuerzos de economía solidaria desde iniciativas comunitarias y micro-sociales de miembros del CCNV y del barrio), la participación en espacios de diálogo político con partidos y movimientos de la Ciudad de Buenos Aires, y, finalmente, instancias de formación y diálogo ciudadano dentro de la iglesia. Con el tiempo, el grupo comenzó a recibir a personas del barrio, que no necesariamente formaban parte de la iglesia oficialmente. Hacia el año 2016, LATE decide fusionarse más activamente con otro de los grandes proyectos del CCNV, el Movimiento No Matarás, que es una campaña de concientización social desarrollada a nivel nacional, con fuerte presencia pública y que articula varios grupos de trabajo dentro de la iglesia. Con ello, LATE se transformará en un espacio más bien operativo dentro del Movimiento, manteniendo un formato de "espiga", donde sus miembros se 
reúnen semanalmente para desarrollar estudios bíblicos y espacios de oración semanales.

En una de las reuniones de coordinación de LATE, uno de sus principales líderes ofreció un análisis de coyuntura sobre la situación de la provincia de Buenos Aires, vinculando el crecimiento de la pobreza con la ausencia del Estado en el distrito al que refería. Esto sirvió como introducción para subrayar la necesidad de empoderar el rol de la Mutual Nueva Vida. Es allí donde se llama a una de las asistentes a compartir su experiencia con la mutual. Ella relata cómo comenzó a producir viandas de comida por necesidad por falta de trabajo, y la experiencia de involucramiento con este proyecto le permitió extenderlo como un emprendimiento que alcanzó a familias del barrio y la iglesia. Al finalizar el relato, dice al grupo: "Estos son los milagros de Dios: cuando ni las injusticias más tremendas de nuestra política y nuestra economía pueden impedir que una siga adelante.” (Mónica, miembro equipo LATE)².

En otra entrevista, uno de los co-pastores hace una relación entre la fe y las cuestiones económicas de la siguiente manera:

\begin{abstract}
Son cosas que la iglesia tiene que proponerse como metas de fe. Y en esas metas de fe yo creo que nosotros tenemos que ir rompiendo barreras con milagros porque estamos en los últimos tiempos. Los milagros no se dan siempre igual. Hay etapas. Hay momentos... Cuando la iglesia entiende en qué tiempo vive, tiene que jugarse con todo... Vivimos en un mundo donde la justicia está muy lejos, y la Biblia dice "haced justicia y amad al prójimo". Cuando uno tiene esa conciencia como cristiano tiene que cambiar la manera. Y es ahí donde actúa la fe. Porque si el hombre no da respuesta a las necesidades de la gente... si los gobernantes, si los empresarios, si los economistas, si los financistas, no dan respuestas... y... ahí tenés que meterle fe y esperar que Dios haga milagros. Y nosotros tenemos esa posibilidad de romper con ese estatus quo a través de la fe. O sea: la fe que usamos para que se sane un enfermo de cáncer, usarla también para que se salga de una situación económica. (Claudio B., miembro del equipo pastoral del CCNV). 3
\end{abstract}

Uno de los aspectos donde estos procesos de resignificación se manifiestan es en la misma comprensión de la práctica de evangelización. En el imaginario evangélico, ésta suele asociarse con acciones proselitistas, donde predomina un discurso focalizado en la "salvación de las almas", cosmovisión

\footnotetext{
2 Testimonio recogido en reunión LATE, Templo CCNV. Capital Federal, julio 2016.

3 Entrevista personal. Capital Federal, marzo 2016.
} 
teológica con implicancias tanto antropológicas como eclesiológicas y teológicas (especialmente, en lo que refiere a nociones escatológicas que promueve la salvación después de la muerte). Es decir, la evangelización se relaciona, en estos casos, con predicar a personas para que se "conviertan”, y así asegurar su salvación eterna, además de recibir con ese acto la venia para ser reconocidos/as "hijos/as de Dios", y con ello el acceso para ser miembros oficiales de la iglesia. La evangelización tiende a ser sinónimo de proselitismo, o sea, una práctica centrada en el crecimiento numérico de la iglesia.

El discurso del CCNV va por otra dirección, aunque no necesariamente la excluye. En otra entrevista con Guillermo Prein, se refleja muy claramente la cosmovisión del $\mathrm{CCNV}$ en esta área, donde lo plenamente pentecostal, la definición evangélica de evangelización y una comprensión más amplia en términos de compromiso social con el sujeto, se entrelazan de la siguiente manera:

\begin{abstract}
Muchos me hablan de la salvación del alma... Por supuesto, por eso las campañas que hacemos... Sanidad divina, milagros y poder: nosotros somos pentecostales hasta la médula. Creemos en milagros hasta más no poder. Pero después que es salva la persona necesita trabajar, necesita desarrollarse, necesita ser feliz. Y yo no puedo pensar que la iglesia los abandone y diga: "bueno, que vivan como puedan". (Guillermo Prein, pastor principal). 4
\end{abstract}

Podemos ver en este relato que la concepción de la salvación del alma permanece, al igual que la importancia de la predicación y la "aceptación del mensaje" como mediación. Pero ello se conjuga inmediatamente con una inscripción del (nuevo) creyente en una situación vital que abarca lo económico, lo político, lo social, lo relacional. De alguna manera, esto se diferencia de la concepción tradicional evangélica, ya que los cambios de vida en el creyente vienen, más bien, como “consecuencia” posterior al acto de conversión. En el CCNV, los medios y caminos para este proceso pueden ser distintos: más allá de la existencia de campañas de predicación, la participación en todos los ministerios es legitimada también como "espacios de evangelización”.

Un elemento central de la identidad pentecostal es la subjetividad como corporalidad afectiva. El pentecostalismo da un especial énfasis a lo afectivo,

\footnotetext{
${ }^{4}$ Entrevista personal. Templo CCNV, Capital Federal, marzo 2017.
} 
no sólo en lo que refiere a la experiencia individual sino también a las dinámicas impresas en los momentos litúrgicos, los procesos institucionales y las prácticas rituales dentro de la comunidad. Es precisamente este elemento de empatía personal y comunitaria que hace del pentecostalismo una de las expresiones religiosas con mayor alcance. Esto se trasluce inclusive en las propuestas de estructuración eclesial, como vemos en el caso de las espigas dentro del CCNV, cuyo objetivo es estrechar lazos más íntimos entre los miembros de la comunidad, como también lograr un alcance dentro de los distintos barrios. 5

Este tema nos trae a colación, nuevamente, un área importante dentro de diversos abordajes contemporáneos, como es la dimensión afectiva de lo político. Chantal Mouffe (2009) afirma que los teóricos políticos suelen olvidarse de las pasiones como elemento constitutivo de las dinámicas sociales, determinando los procesos de identificación sólo a movimientos conscientes, formales y racionales (MOUFFE, 2009). Por el contrario, las dinámicas sociopolíticas están enlazadas al elemento del goce o, en términos lacanianos, a la jouissance como dimensión libidinal/visceral/afectiva tanto personal como colectica, entrando en juego con el proceso de identificación (STARVAKAKIS, 2007; 2010) Como afirma Jorge Alemán, partiendo de una relectura de las propuestas de Ernesto Laclau (ALEMÁN, 2014), las demandas no deben ser pensadas sólo desde la insatisfacción sino también desde el deseo, ya que toda demanda tiene por objetivo satisfacer un gesto de aceptación e inclusión dentro de un espacio de negación.

\footnotetext{
5 El sistema de espigas es un programa complementario del CCNV a las liturgias semanales en los lugares centrales de culto. Consiste en la formación de pequeños grupos que se reúnen cada semana en casas de familia o en alguno de los templos del Centro. La cantidad de espigas oscila entre 800 y 900 según la etapa del año. Existen dos tipos de grupo. Por un lado, los $\mathrm{ABC}$, que representan espacios de encuentro de no más de cinco a seis personas, cuyo objetivo es atender a quienes recién ingresan a la iglesia, para introducirlos a la dinámica de la comunidad, como también conocerles y ofrecer un espacio de contención y oración. Por otro, las espigas propiamente dichas, las cuales son dirigidas por algunos de los líderes ya reconocidos por la comunidad, donde se realiza un estudio bíblico de mayor sistematización y en consonancia con los ejes centrales de formación propuestos por el CCNV cada año. A pesar del parecido de este esquema con el reconocido "sistema celular" o "programa de células" del modelo de "iglecrecimiento" que estuvo muy en boga dentro de espectro evangélico en los '9o, presenta distinciones considerables. La diferencia reside en el hecho de que, mientras el sistema celular posee un importante énfasis en el crecimiento numérico de las iglesias, el sistema de espigas desarrollado por el CCNV busca más bien ampliar los espacios de liderazgo, seguimiento y formación de las bases, tanto para su "discipulado" en relación con los elementos básicos de la fe como con relación a su preparación para el trabajo dentro de la iglesia.
} 
Desde esta mirada, la vinculación que existe dentro del CCNV entre el enfoque en "la gente" y sus necesidades personales, los espacios de socialización focalizados en pequeños grupos de acompañamiento y el énfasis en la dimensión corporal y afectiva de la espiritualidad, y la misma percepción sobre la presencia de Dios manifiesta en la vida de cada creyente, comportan un abordaje más integral de las demandas sociales y una noción multidimensional de lo político.

Al preguntar dentro del CCNV sobre cómo lidian con la pluralidad de posiciones y diferencias políticas que nacen en medio de estos procesos, obtuve tres tipos de respuestas. Primero, la apropiación de la imagen del pastor principal, Guillermo Prein. Más allá de las diferencias que existían con sus perspectivas particulares, su investidura pastoral posee suficiente poder simbólico como para que todo el grupo de liderazgo se sienta unido tras su persona, intentando no mostrar fisuras, al menos en cuestiones prácticas con respecto a la institución o administración eclesial.

También existía la posibilidad, como segunda respuesta, la preferencia a no tocar temas políticos de manera "explícita", al menos mencionar nombres (de funcionarios) o partidos. Sin embargo, en la vida cotidiana de la iglesia este principio no siempre se cumplía, ya que tanto en las reuniones de LATE, como de otras áreas -como el Movimiento No matarás- o las mismas predicaciones de Prein, muchas veces se hacía referencia a figuras y partidos políticos con nombre y apellido. Lo que podemos notar es que las críticas eran parejas para casi todas las expresiones, desde el oficialismo por entonces a nivel nacional (el kirchnerismo) como el local (el gobierno de Propuesta Republicana -PRO- en la ciudad).

El último elemento - que profundizaremos más adelante - es que el "enfoque en la gente" como un elemento aglutinador, conllevaba priorizar la atención a la necesidad de las personas por sobre cualquier bandera política particular. En este sentido, la apelación de la fe como cuidado por el prójimo primaba más que las ideologías políticas específicas; o más bien, el enfoque en la gente articulaba un diálogo e intercambio entre diversas miradas. 
Podemos concluir que la sensibilidad de parte de la membresía del CCNV con respecto a posicionamientos críticos (tanto políticos como teológicos) iban cambiando, mutando y afianzándose en la medida que las personas se involucraban con mayor compromiso dentro de la estructura de liderazgo de la iglesia. Esto, a su vez, nos muestra entonces que una mayoría de base en la congregación estaba más focalizada en la asistencia a necesidades básicas con respecto al desarrollo de prácticas religiosas, demandas personales y necesidades espirituales, que en desarrollar un posicionamiento teológico y políticos profundo, como lo podemos ver en el liderazgo extendido.

En resumen, podemos afirmar que el CCNV se comprende como una comunidad pentecostal que revaloriza explícitamente cada uno de los elementos de su expresión identitaria, a saber, el lugar de los milagros y las curaciones como evidencias de manifestación divina, la práctica de la palabra profética como instancia hermenéutica, y una antropología afectiva y corporal como formas de construir procesos de identificación subjetivas y colectivas. Pero esta pentecostalidad no es abordada de manera homogénea o desde fronteras estables, sino -siguiendo el "espíritu” del liderazgo de la iglesia- buena parte de la comunidad (especialmente aquellos miembros más activos, no sólo los concurrentes a las liturgias) lo asume de forma disruptiva, es decir, cuestionando los modos tradicionales de comprender la pentecostalidad, el cristianismo, lo evangélico y lo sociopolítico.

\subsection{Identidad eclesial y práctica política: la "gente" como significante flotante}

"Pasión por la gente" es uno de los principales lemas del CCNV. Es un término recurrente tanto en el discurso del liderazgo como en el resto de la congregación. La importancia de este eslogan reside en ser un significante que concentra un conjunto de procesos simbólicos, relacionales, institucionales y políticos dentro de la iglesia, que produce principalmente dos efectos: por un lado, una resignificación de diversos discursos teológicos (sea en relación con el pentecostalismo como con el campo evangélico en general), y por otro, de la propia cosmovisión sociopolítica de la comunidad. En este sentido, la presencia 
de la gente en el imaginario del CCNV se presenta también como instancia disruptiva que reconfigura prácticas y discursos teológicos.

La gente emerge como un significante que cuestiona, por una parte, diversas visiones políticas tradicionales presentes tanto en el CCNV, en particular como en el campo evangélico en general, especialmente las que refieren a la extendida comprensión en torno a la "impureza” de la práctica política y la necesidad de construir nuevos marcos de intervención social a partir de las acciones eclesiales.

En este sentido, encontramos que este significante faculta una definición alternativa o más amplia de la misma comprensión de política, especialmente a partir de lo que Giddens denomina como "política de la vida” (GIDDENS, 1991), donde la microfísica de las experiencias cotidianas en las comunidades y los individuos (tanto creyentes como del barrio) cobra un lugar central en tanto epicentro político. Ello también concierne a lo desarrollado anteriormente respecto a la necesidad de ver la política más allá de la institucionalidad partidaria y el lugar central-casi mesiánico y escatológico- percibido por parte de la iglesia en esta transformación. Por ello, este conjunto de reapropiaciones tiene directa relación con la perspectiva misionológica del CCNV, o sea, de su ser-eclesial en el mundo.

Así lo describe Daniela - miembro del CCNV, con un pasado dentro de la iglesia de Hermanos Libres, abogada, militante de una agrupación política de izquierda y participante en LATE y del Movimiento No matarás - quien hace una vinculación entre la práctica eclesial y su foco en las personas, describiéndolo como una "visión populista":

Tenemos esa visión populista de remarcar a personas antes que la doctrina [...] Vos lo escuchas a Guillermo de manera privada y el siempre dice: "no es bueno eso [...] que las personas digan: lo dice el pastor y lo hago". El dice: "no, vos no tenés que hacer las cosas porque yo te lo digo. Vos tenés que hacerla por una convicción cristiana". (Daniela A., miembro de LATE). ${ }^{6}$

En este relato encontramos uno de los elementos principales del uso del significante gente en el discurso del CCNV, presente en un sector de la

\footnotetext{
${ }^{6}$ Entrevista personal. Capital Federal, octubre 2016.
} 
congregación: el eje más importante que encausa el ser y hacer de la iglesia son las necesidades de las personas, no el cumplimiento de un dogma o un tipo de moralina religiosa. Es decir, hay un fuerte énfasis y advertencia en que las ideas teológicas y las prácticas eclesiales deben ir al ritmo de las demandas sociales, y no al revés. Esto lo hemos desarrollado al analizar la persona de Prein y la comprensión identitaria de la propia comunidad (PANOTTO, 2020): su intento de romper con los esquemas habituales del campo evangélico -los cuales son descritos dentro del CCNV como "conservadores", "fundamentalistas" o "tradicionalistas" -, para erigirse como un espacio nuevo (desde donde se redefine lo religioso, lo evangélico y lo pentecostal), a partir del foco en las personas y no en las prerrogativas religiosas, aunque su inspiración sigue siendo la misma fe (pentecostal).

Este elemento puede advertirse en las palabras de Daniel, otro miembro de la iglesia y también militante político, referente entre las organizaciones de defensa del consumidor en Capital Federal. Al igual que Daniela, comenzó su peregrinaje religioso en otra denominación - en este caso, la iglesia bautista -, aunque sus búsquedas tanto espirituales como políticas lo llevaron finalmente al CCNV. En este caso, vemos cómo lo religioso apela al sentido político, pero también cómo este último es resignificado y hasta complementado con ciertas lógicas religiosas, en especial desde elementos de la cosmovisión pentecostal, como es el lugar de la profecía y los milagros:

Yo buscaba un lugar con la visión política similar a las iglesias de FAIE [Federación Argentina de Iglesias Evangélicas] pero que fueran pentecostales [...] Es difícil encontrar un lugar así. Pero necesitábamos un lugar donde se reflexione sobre la actualidad social y política, y sobre las necesidades de la sociedad -al estilo de las iglesias de FAIE [...] pero que no deje de valorar la experiencia personal, la alabanza [...] No siento que es un choque entre una propuesta o la otra. Siento más bien que las cosas tienen que ir juntas [...] A veces, estas palabras [profecías] te muestran en qué lugar actuar, dónde trabajar. Y ahí ves cosas que exceden tu participación. Estos son milagros. (Daniel B., miembro de iglesia). ${ }^{7}$

Se pueden destacar dos elementos de análisis centrales para comprender la ontología política del pentecostalismo desde estos fragmentos: el lugar de los significantes vacíos y la dinámica articuladora de las demandas sociales. Con respecto al primero, vemos que en el CCNV se utilizan diversos términos o ideas

\footnotetext{
${ }^{7}$ Entrevista personal. Capital Federal, marzo 2016.
} 
que permiten concatenar y resignificar ideologías o cosmovisiones de las más variadas (LACLAU, 1996). Estas segmentaciones discursivas imprimen la tensión, destacada también por Ketzer (1988), con respecto a la simultánea condensación y ambigüedad de un símbolo. En esta dirección, un significante posee un pluri-sentido, donde su estructura particular habilita diversas interpretaciones, provocando con ello una instancia de ruptura con otros órdenes discursivos establecidos (PANOTTO, 2013).

En el caso del CCNV, por ejemplo, vemos que la gente se transforma en un significante que es definido desde el ministerio de Jesús entre los más pobres, como expone el texto bíblico, hasta como llamado a una sensibilidad por los necesitados y sufrientes dentro de la comunidad hoy. "La iglesia se extiende donde está la necesidad, donde está la gente", afirmó uno de los pastores en un culto dominical. Este significante, que posee una referencia tanto bíblicoteológica como contextual, es referida en el CCNV tanto por el liderazgo como por la membresía en general como una manera de apelar a la "militancia" sociopolítica desde una mirada más amplia, donde se pueden articular diversas ideologías, cosmovisiones socio-políticas y preferencias partidarias. Lo prioritario es la experiencia personal del Espíritu y el alcance a la gente, lo cual puede evocar todo tipo de prácticas. Los modos particulares desde dónde se operen las acciones, o inclusive las ideologías políticas de los sujetos, quedan en un lugar secundario.

Este elemento nos lleva a preguntarnos por la necesidad de complejizar o, si se quiere, radicalizar- la distinción que hace Hilario Wynarczyk (2009) entre el paso de un dualismo negativo a un dualismo positivo dentro de ciertas expresiones pentecostales con respecto a la cosmovisión del "mundo" y su deber moralizador (WYNARCZYK, 2009). Aunque en el CCNV persiste una mirada dualista, ella no refiere solamente a la comunidad eclesial como agente moralizador en un mundo demarcado y visto, además, desde un juicio estrictamente negativo. No existe una frontera tajante entre fe y mundo, sino más bien un dualismo ontológico que funciona como mecanismo disruptivo dentro de la historia, haciendo de ella un escenario de posibilidades y pugnas de sentido, más que de distinciones metafísicas (PANOTTO, 2016). El lugar que ocupan los significantes vacíos hace que ciertos valores o sentidos sociales sean 
leídos teológicamente desde la mística de la fe, donde algunos inclusive no son estrictamente religiosos (como la gente, la militancia, o el mismo sentido de política).

En resumen, ponemos en cuestión la distinción de dualismo positivo como separación entre identidad de fe y mundo, pensando más bien en la ubicación de ciertos discursos socio-políticos de matriz teológica, que marcan una frontera tanto interna (en la iglesia) como externa (con ciertos grupos eclesiales, políticos, sociales, o inclusive concepciones de la realidad política, cultural y económica), que enmarca la iglesia, el "mundo" y otros espacios y agentes de manera conjunta, mas que desde una división radical de fronteras entre ellos.

El hecho de que la construcción de prácticas e imaginarios políticos en el CCNV se enmarquen en la atención a la necesidad de la gente, nos lleva a un segundo elemento analítico, a saber, el lugar de las demandas sociales como epicentros de construcción identitaria (LACLAU, 2005; ARDITI, 2011). Esto sugiere que una demanda se transforma en articuladora de un conjunto de discursos, prácticas e identidades con el objetivo de responder a dicha carencia, problemática, coyuntura, deseo o necesidad. En este proceso, alguno de estos elementos deviene en punto nodal para provocar una acción conjunta entre distintos discursos, cosmovisiones y prácticas institucionales. Lo más importante es subrayar que una identidad política comprendida como articulación de significantes a partir de la atención a una demanda, abre el sentido de lo político más allá del énfasis o asunción de un discurso ideológico particular.

Esto se trasluce en las palabras de Sergio, uno de los primeros pastores del CCNV, quien resalta la diversidad de posicionamientos políticos dentro de los grupos, a partir de la prioridad que tiene la atención de los problemas cotidianos de las personas:

Yo creo que el mensaje que viene, apela a que cada uno sea responsable de su vida y de sus cosas. No hay un partidismo, por así decirlo. O sea, el abanico está. Si vos viniste a la Iglesia por un problema de enfermedad. Llegaste a un hospital, te evangelizaron en un hospital, te invitaron a la Iglesia y llegaste. Y vos en tu corazón sos peronista - por así decir - y no dejás de ser peronista por más que te 
encontrés con gente de otros partidos. Aquí cuando fue lo del gobierno de la ciudad, las elecciones, en las comunas vos tenías de todo. Cada partido ponía sus representantes. Yo tengo amigos que están en el lado de la Carrió, amigos, gente conocida que están en todas las áreas y yo estoy lo más bien con ellos, no tengo problemas. Porque de mí, yo acepto la diversidad. No hay un partidismo, no hay un mensaje partidista, derecha, izquierda o centro. Aquí cada uno... Vos le preguntás a cualquiera y vas a intervenir en charlas donde uno dice: "Yo estoy en contra de esto", "pero a vos qué te parece esto". Y todos compartimos acá el mismo Dios, por así decir, pero cada uno tiene su perspectiva política. (Sergio L., miembro de la iglesia). ${ }^{8}$

Como ya hemos dicho, el énfasis que pone el pentecostalismo en la atención de las necesidades personales y sociales conlleva la construcción de una concepción de lo sociopolítico más cercano a la vida cotidiana de las personas de la comunidad y de los creyentes. Este elemento relacional propio de la mística pentecostal y del congregacionalismo evangélico en general, conllevan pensar en las prácticas políticas desde una perspectiva micro, que prioriza acciones transformadoras antes que en tipos de identificación ideológica.

La experiencia de LATE nos ayuda a analizar lo que afirmábamos respecto a la resignificación de imaginarios sociopolíticos desde la especificidad teológico-religiosa del discurso y práctica eclesiales. Por un lado, este ministerio se asume a sí mismo como un espacio de diálogo y reflexión, desde donde se puede discutir lo que sucede en el ámbito social, tomar conciencia de sus problemáticas y pensar en acciones concretas de intervención como iglesia. Por ello, esta agrupación ubica su tarea política - la cual, a su vez, es entendida como una actividad ligada a la misma fe - en una instancia de ruptura con respecto a ciertos discursos instalados a nivel social y también religioso (por ello, es muy común escuchar repetidas veces en las reuniones de esta agrupación cuestionamientos a los discursos conservadores de ciertos cuerpos evangélicos y católicos):

Hay que saber. Hay que visibilizar para que la gente no se coma lo de los medios. (Claudio, Equipo pastoral). 9

Eso también es pastoral: informar a la gente sobre economía social, sobre lo que pasa con lo que la gente compra. (Leonardo, católico, miembro del equipo LATE). ${ }^{10}$

\footnotetext{
${ }^{8}$ Entrevista personal. Capital Federal, marzo 2015.

${ }^{9}$ Nota tomada de Reunión de planificación LATE. Templo CCNV, Capital Federal, julio 2017.

${ }^{10}$ Nota tomada de Reunión de planificación LATE. Templo CCNV, Capital Federal, julio 2017.
} 
Como el pueblo te hablo: yo, como CCNV, estoy informada. Pero la gente, el resto, de abajo, del medio y arriba, no sabe nada. (Felicitas, miembro del equipo LATE). ${ }^{11}$

Es sugestivo notar cómo las dinámicas propias del CCNV en tanto institución eclesial son descritas en términos políticos. Esto lo vemos en las palabras de Daniel, quien utiliza un lenguaje cargado de sentido social para describir los modos de organización institucional de la iglesia, e inclusive sus tensiones:

La unidad no es uniformidad [...] Sí hay una tensión constante entre los liderazgos religiosos y el planteo de algo asambleario, democrático [...] El juego es saber manejar una palabra de parte de Dios que, por ejemplo, se que hay palabras proféticas, orientadoras [...] Manejarlo junto con [...] esto del "Papa infalible" [...] Parece que algunos evangélicos lo tomaron más fuerte que en el catolicismo [...] Entonces, después, cualquier palabra que dice el pastor o líder, es una palabra que hay que respetar a rajatabla. (Daniel B., miembro de la iglesia.) ${ }^{12}$

Como afirmábamos anteriormente, todo esto pone de manifiesto que las formas de organización eclesial y los discursos teológicos permiten ser comprendidos desde significantes sociopolíticos, como también, desde una dinámica inversa, las mismas prácticas religiosas y discursos teológicos habilitan instancias de imaginación política. En este sentido, el significante de la gente actúa como un elemento aglutinador de estas cosmovisiones, haciendo de la práctica social del CCNV, en su foco sobre las personas más que en responder a su institucionalidad como fin en sí mismo, un espacio de articulación nodal entre visiones teológicas, religiosas y sociopolíticas.

\section{Resignificaciones políticas desde el discurso teológico}

\subsection{La Biblia, la "Palabra" y el empoderamiento de subjetividades hermenéuticas}

La Biblia representa el principal elemento de resignificación de nociones sociopolíticas, en el campo evangélico en general y el pentecostal en particular. Ella siempre es utilizada como marco de construcción significante, especialmente a través de la evocación de relatos, historias y principios

\footnotetext{
${ }^{11}$ Nota tomada de Reunión de planificación LATE. Templo CCNV, Capital Federal, julio 2017.

${ }^{12}$ Entrevista personal. Capital Federal, marzo 2016.
} 
teológicos. En el caso de LATE, los relatos proféticos y la vida histórica de Jesús en los Evangelios sirven como arquetipos para redefinir diversas nociones, tales como la acción política, la necesidad de lograr cambios culturales, la militancia, la importancia del pluralismo, entre otros. Como dice Claudio, miembro del grupo pastoral:

Uno es $\mathrm{K}$, uno es... Uno no es nada. Uno es de la gente. ¿Dónde aprendiste eso? En la Biblia [...] Yo creo que el Evangelio en sí es poder para cambiar. Es poder de Dios. Y tiene un compromiso social desde siempre. Porque vos cuando agarras la Biblia ves que muchos hombres de Dios, fueron en su tiempo estrategas, reyes, presidentes; o sea, eran líderes. Pero líderes del pueblo y líderes políticos. (Claudio B., Equipo pastoral). ${ }^{13}$

Como también hemos afirmado, no sólo los discursos bíblico-teológicos sino también las prácticas institucionales en el seno mismo de la iglesia sirven a la reapropiación de nociones y prácticas, tales como la militancia, lo democrático, la ciudadanía, entre otros. En este sentido, la iglesia se transforma en muchos casos en un modelo o espacio de facilitación, tanto de la puesta en práctica de estas nociones como también de su realidad concreta dentro de la comunidad social.

Y ese es el tema: a la gente le cuesta participar. A la sociedad le cuesta. Porque si lo rompemos en la iglesia lo rompemos en la sociedad. Porque en definitiva son los mismos temas. (Claudio B., Equipo pastoral) ${ }^{14}$

Una democracia participativa donde después haya una instancia donde debe haber participación y colaboración en las decisiones que tienen que tomar los participantes, y una participación permanente, $\mathrm{y}$ bueno... Me parece que es la que más refleja la visión de Dios, el pensamiento de Dios, la esencia de Dios, donde la espiritualidad de la persona también refleja un desarrollo en estas áreas, en la toma de decisiones, no sólo con respecto a sus propias vidas sino también con otros. Y me parece que eso, el ámbito especial para desarrollarlo, es la iglesia, la cual no sólo te pide que participes sino que te deje elaborar también la participación, ¿no? (Daniel B., miembro del equipo LATE). ${ }^{15}$

Con respecto a los esquemas auto-referenciales que demarcan la identidad del CCNV, vale resaltar su pluralidad constitutiva. Ello lo podemos atribuir, principalmente, a factores eclesiológicos y teológicos. En primer lugar, hay un elemento componente de las iglesias evangélicas, que es la interpretación

\footnotetext{
${ }^{13}$ Entrevista personal. Capital Federal, febrero 2016.

${ }^{14}$ Entrevista personal. Capital Federal, febrero 2016.

${ }^{15}$ Entrevista personal. Capital Federal, marzo 2016.
} 
personal del texto bíblico sin mediación externa. Los creyentes se transforman en sujetos hermenéuticos, que construyen el sentido del texto bíblico a la luz de sus experiencias y ámbitos, los cuales son, a su vez, leídos particularmente a partir de los elementos interpretativos que emerjan del ejercicio (PANOTTO, 2014).

Los encuentros de reflexión bíblica a los que asisten la mayoría de los participantes del CCNV (principalmente las espigas), se transforman en espacios de diálogo y reflexión sobre las diversas interpretaciones de la Biblia desde las experiencias concretas de los participantes. Estos mecanismos se radicalizan aún más dentro de la cosmovisión pentecostal, la cual promueve con más fuerza que otras expresiones evangélicas la importancia de la experiencia espiritual individual y de los testimonios personales como relatos que sirven de marco interpretativo para estas lecturas bíblico-teológicas.

En este sentido, el texto bíblico se transforma en un campo narrativo que resignifica experiencias y sentidos sociopolíticos. Esto es muy común en varios de los escritos de Guillermo Prein (2013), como por ejemplo en este texto donde refiere a las dinámicas económicas de la Argentina en la última década:

Sudando con el pueblo, olimos a ovejas empapadas en desesperación. A puro milagro salimos adelante, como guerreros contra la muerte. Con saladas lágrimas de dolor y alegría... sazonamos nuestra Patria herida [...] Diez años de cosechas magníficas y precios internacionales extraordinarios levantaron al país de su peor tumba, pero a su vez, activaron la levadura de mezquinos expertos en artimañas. Aquel silencio fue destrozado por sobrinos impertinentes... todos hablaban... hablan y hablan. Parecido a las parábolas bíblicas [...] Moab, sodomita, siempre oprime a quienes migran en su debilidad; y, aún cuando la verdad yuxtaponga sentimientos en nuestra alma, tenemos que tirar al mar a todos los jonases... para que mediten en la solitaria y húmeda barriga de la ballena y de esa forma cambien, si es que quieren formar parte de la Patria, que viva se desarrolla y toma forma cada día. (PREIN, 2013).

El CCNV ubica en un lugar central la acción e intervención de los creyentes, no sólo como intérpretes del texto bíblico sino como sujetos activos dentro de la vida de la iglesia. Sebastián, un miembro de la iglesia - también vinculado a actividades políticas - dice lo siguiente: "Lo que a mí me habla es que cada uno que tenga una intencionalidad hacia un área, le dan ahí... Y eso 
habla de que cada visión, cada ocasión, cada deseo, cada llamado, se puede canalizar”. (Sebastián S. miembro de la iglesia) ${ }^{16}$.

Otro de los miembros del cuerpo pastoral del CCNV, Carlos, afirma:

Todo el mundo, cada uno es importante. Y cada uno desarrolla en la amplitud de lo que puede desarrollar... cada uno no tiene un límite sobre cómo desarrollarse, de poder participar. Porque la gente, todo el mundo que está interesado, puede participar, cosa que vos en muchos otros sectores no podés participar... totalmente, libremente. (Carlos S., miembro de la iglesia). ${ }^{17}$

Estos relatos evidencian dos elementos centrales en relación con la definición identitaria del CCNV con respecto a la apertura hermenéutica de sus miembros: la importancia del sujeto creyente como agente activo y la comprensión heterogénea de lo eclesial. Esto deriva en la importancia de la pluralidad constitutiva del CCNV, que se comprende a sí mismo como un actor social compuesto por un conjunto de individuos, que a su vez representan cosmovisiones y discursos en tensión. Por ejemplo, el coordinador de LATE describe el grupo de la siguiente manera:

[...] LATE es un espacio plural, políticamente hablando. Y es lo que más defiendo; defiendo con todo eso. Porque para nosotros es muy importante que dentro de LATE pueda convivir alguien de Frente para la Victoria, alguien de Proyecto Sur, alguien del PRO, alguien de lo que se le cante, porque que en definitiva nos une un proyecto que sea para el bien común. (Carlos B., coordinador LATE y parte del equipo pastoral) ${ }^{18}$.

Nuevamente vemos que existe un elemento siempre evocado como catalizador del trabajo conjunto, más allá de las divergencias ideológicas y políticas. En este caso, el impulso de la fe para el compromiso con el prójimo actúa como una frontera de articulación, a pesar de las tensiones ocasionadas por las diferencias.

Por último, la dinámica de LATE se inscribe en una lógica hermenéutica muy común dentro del pentecostalismo, que es la apelación a experiencias personales (de lo divino) como locus para releer la realidad, lo cual posiciona al creyente como un sujeto activo en la interpretación y dinámica del contexto. En

\footnotetext{
${ }^{16}$ Entrevista personal. Capital Federal, agosto 2017.

${ }^{17}$ Entrevista personal. Capital Federal, octubre 2016.

${ }^{18}$ Entrevista personal. Templo CCNV, Capital Federal, julio 2016.
} 
este sentido, el relato de testimonios forma parte de la agenda en todas las reuniones de LATE. El lugar del testimonio conforma una trama hermenéutica donde convergen caracterizaciones contextuales, interpretaciones personales y construcciones teológicas, las cuales actuarán como marco de sentido de resignificaciones sociopolíticas.

A través de estos ejemplos podemos advertir que el sentido de pluralidad y de acción por parte de los sujetos concretos tiene un lugar central en el CCNV, no sólo como un elemento coyuntural sino como parte de una cosmovisión sociopolítica en el amplio sentido. Lo que vale resaltar es que dicha cosmovisión no deviene solamente de un enmarque filosófico o ideológico estrictamente "político" sino principalmente desde las caracterizaciones distintivas de la construcción de lo eclesial, los discursos teológicos y de las prácticas religiosas, reflejado particularmente en la posibilidad de interpretar el texto bíblico desde aprehensiones muy diversas y experienciales.

En otros términos, la reivindicación del sujeto creyente como constructor de sentido o como un actor de valor particular dentro de la institución por su experiencia con Dios -elementos representativos de la cosmovisión evangélica y pentecostal- son instancias que, desde su especificidad, permiten la afirmación de una identidad en el sentido sociopolítico (LÓPEZ, 2000).

\subsection{Espíritu y espiritualidad: la encarnación de la acción divina}

Una de las particularidades del pentecostalismo radica en el énfasis en la figura del Espíritu Santo. Este es un elemento teológico históricamente afín a las dinámicas de ruptura y cambio dentro de la iglesia, como también originador de llamamientos especiales a personajes importantes en momentos coyunturales de la historia religiosa y, dentro del texto bíblico, simboliza la manifestación divina que apela al movimiento -la ruaj (viento)- que va y viene sin control, y que se revela en la historia a través de algún suceso innovador. En otros términos, la imagen del Espíritu evoca al cuestionamiento de cualquier tipo de ortodoxia institucional, dogmática, existencial o discursiva.

En el caso del CCNV, la invocación al Espíritu responde a la cosmovisión de una iglesia pentecostal promedio. En las liturgias - sean durante la semana o 
en las reuniones principales de los domingos- la mención a la "presencia” del Espíritu se evoca desde diversos mecanismos: experiencias extáticas que se reflejan en sensaciones corporales - "tócanos Espíritu”, "siente el Espíritu”, “deja que el Espíritu te llene” -, cuya manifestación se exhibe a través de diversos gestos, como el alzar las manos, el cerrar los ojos, aplaudir, todo ello siempre acompañado de una expresión de profunda emotividad, evidenciada en rostros constreñidos y hasta momentos de llanto por parte de las personas.

Por otro lado, aunque no es una práctica predominante, también se escuchan personas hablando en lenguas (uso de la glosolalia), es decir, cantando, orando o simplemente expresándose a través de lenguajes desconocidos, durante el momento de las liturgias. Esta práctica es muy común en el campo pentecostal, la cual representa no sólo el "sello" del suceso de conversión (a diferencia del resto de denominaciones evangélicas, que no solicita tal confirmación) como también una instancia de mayor profundidad e intensidad en su práctica espiritual.

En el CCNV también podemos encontrar algunas particularidades con respecto a cómo se toma la figura del Espíritu. En primer lugar, es una imagen muy utilizada en discursos comunitarios como instancia de disrupción en la vida cotidiana de los creyentes y de la propia configuración eclesial, sea desde los procesos de diferenciación institucional (con respecto a otras expresiones evangélicas, como también políticas) y las manifestaciones de transformación que manifiestan los creyentes en sucesos concretos en su vida cotidiana. Es decir, la apelación al Espíritu siempre refiere a un hecho de transformación, de cambio, de "revolución", donde las circunstancias tanto individuales como grupales y sociales vivencian una situación de radical metamorfosis, precisamente por la acción directa del Espíritu.

Un segundo elemento en este campo es la centralidad en el cuerpo como medio de manifestación del Espíritu. La experiencia pentecostal está atravesada de vivencias extáticas, expresiones litúrgicas que promueven el movimiento corporal, un énfasis particular en la curación de las enfermedades, entre otros elementos (ALGRANTI, 2010). Esto representa lo que Rodrigo Moulián Tesmer (2017) denomina como la poiética de la encarnación propia del 
pentecostalismo, entendida como la acción de Dios revelada a partir de una “estética de la encarnación”, donde las expresiones del Espíritu están mediadas por manifestaciones palpables a través de demostraciones emocionales, somatizaciones corporales y expresiones estéticas a través de la música y la danza, dos elementos fundamentales de la liturgia del CCNV. Vemos aquí uno de los puntos neurálgicos en torno a lo que podríamos entender como la ontología política pentecostal: más allá del énfasis en la dimensión espiritual como una esfera supra-natural donde opera la fe y la misma revelación divina, ella siempre se proyecta en una instancia no sólo histórica, sino más concretamente corporal.

\subsection{El sufrimiento como dispositivo de agenciamiento}

El énfasis en la dimensión paliativa del sufrimiento también refiere a la acción del Espíritu en cada persona, para tratar desde enfermedades físicas hasta malestares personales y problemas económicos. Aquí vale traer algunas reflexiones de Talal Asad (2003) sobre la relación entre agencia y dolor. Asad plantea que el dolor no sólo causa acción, sino que es en sí mismo acción (ASAD, 2003). Más concretamente, el sufrimiento es un modo de relacionamiento social que crea condiciones para experiencias y acciones particulares, donde cierto uso del padecimiento constituye un espacio de acción moral que conecta la realidad presente con la que viene.

Esta mirada, según Asad (2003), se contrapone a los enfoques tradicionales del ideario moderno donde la agencia tiene que ver con operaciones ordenadas por una conciencia autosuficiente sobre el momento histórico del sujeto, el cual es comprendido sin fisuras, es decir, carente de crisis, sufrimientos o divergencias. Hablar de identidad desde la experiencia del sufrimiento implica hablar de agencia a partir de una espacialidad de representación, donde el dolor conlleva comprender la identidad fuera de un intento de control sobre la situación, y donde el "deseo de sanidad" implica "ser controlado por el mundo", como una forma de generar una acción de incidencia sobre éste. Implica reconocer que la realidad y el propio ser se constituyen en la práctica, a partir de "un mundo donde se acumulan probabilidades antes que certezas" (ASAD, 2003, p. 73), sentimiento que se presenta sólo a partir de la 
angustia como una instancia de inseguridad, inestabilidad y cuestionamiento del lugar del sujeto.

Esta capacidad movilizadora que posee la experiencia del sufrimiento la podemos ver, por ejemplo, en las palabras de Alejandra, una líder de la iglesia vinculada con el ministerio de las espigas en el CCNV, que afirma lo siguiente:

\begin{abstract}
Entonces nos dimos cuenta que la sociedad, o la gente que está en la sociedad, algunas, algunos de ellos son injustos, y que hay mucho sufrimiento y mucho dolor porque hay muchos que son injustos. Entonces ahí viene, y yo creo que aquí el llamado o el momento de comprensión que vos estás queriendo aclarar, es cuando entendimos que cada uno es responsable. Yo soy responsable. (Alejandra A., miembra del CCNV). ${ }^{19}$
\end{abstract}

Podemos ver en esta afirmación una cosmovisión muy recurrente en el discurso del CCNV y del pentecostalismo en general: las situaciones de sufrimiento, crisis y dolor en las personas representan una posibilidad para ver la acción de Dios, y de esa manera enmarcar la agencia de los sujetos desde una instancia positiva. Esto comprende ver el dolor como una forma de acercarse a la fe y la iglesia, pero principalmente como un terreno en el cual los creyentes son constantemente "puestos a prueba" (por las circunstancias, por el diablo o por Dios mismo) para aprender a mejorar su espiritualidad, y por ende su personalidad.

El sufrimiento, entonces, no apela sólo a un momento de debilidad que abre la puerta a la conversión (como generalmente se tiende a leer dentro de cierto imaginario evangélico) sino como un marco que delinea un tipo de antropología activa/actuante en torno a las posibilidades de cambio de los sujetos creyentes, en quienes el dolor y la adversidad se transforman en una frontera para descubrir, construir e intervenir desde nuevos lugares que, por supuesto, son creados por la intervención de Dios.

Tal como plantea Asad (2003) sobre el hecho de "ser controlados por el mundo" (es decir, atravesados por el exceso de la realidad en que se inscribe el sujeto y sus posibilidades-de-ser), en este caso, el hecho de que "todo está bajo el control de Dios", tal como se proclama constantemente dentro de la

${ }^{19}$ Entrevista personal. Templo CCNV, Capital Federal, diciembre 2017. 
cosmovisión teológica del CCNV, habilita un lugar de nuevas posibilidades de vida, que ubican al creyente como un sujeto activo y a la vez (pre)dispuesto a adentrarse o enfrentarse a nuevos escenarios existenciales a partir de las puertas abiertas por lo que se entiende como la misma intervención extraordinaria de Dios en esas circunstancias también fuera de control.

Como se suele decir en la jerga evangélica, las dificultades son instancias de "perfeccionamiento" que "ponen a prueba" a la persona. Esto se relaciona, como veremos más adelante, con el hecho de que la sumatoria de dificultades atravesadas -las cuales siempre se expresan a través de los testimonios en los momentos de liturgia o en las espigas-, sea visto como una forma de jerarquizar el estatus de legitimidad de las personas dentro de la comunidad eclesial. Es decir, quien más posea experiencias de sufrimiento, las cuales son superadas en instancias milagrosas o donde se de testimonio de que Dios actuó de alguna manera especial, contará con mayor legitimidad dentro de la iglesia como "creyente maduro" e inclusive con más respaldo para ocupar un lugar de liderazgo o consejería.

\subsection{Reino de Dios: demarcaciones para una ontología política}

El concepto de reino de Dios es uno de los más importantes dentro de la tradición cristiana. El mismo remite a la escatología bíblica y se encuentra presente tanto en el Antiguo Testamento como en el Nuevo Testamento. Apela a una acción futura de Dios en la historia, sea para liberar al pueblo de Israel o juzgar a la humanidad. Las lecturas contextuales que germinaron a partir de la década de los '70, especialmente desde la teología de la liberación en América Latina, trabajan este concepto desde un estudio de la vida histórica de Jesús, especialmente de su labor con los pobres, y su denuncia a los poderes religiosos y políticos. Aunque esta tradición específica no influyó considerablemente en la iglesia pentecostal, sí lo hizo cierta lectura matizada que afirma que el reino de Dios no es sólo una realidad futura sino una condición que comienza a gestarse en el presente a través de la acción de los creyentes en la sociedad. 
Este abordaje sobre el reino de Dios se encuentra muy presente dentro del CCNV. Vemos, por ejemplo, que Guillermo Prein (2008) afirma lo siguiente en una reflexión bíblica respecto a este tema:

Un texto clave para entender tu tiempo y tu identidad es Lucas 10: Obedecer al Maestro, evangelizar, recibir provisión divina, la manifestación de milagros y poder de Dios, el diablo derrotado y nosotros gozándonos porque nuestros nombres figuran en el libro de la vida. Viviremos con Él por la eternidad la que, dicho sea de paso, comienza en esta tierra y por eso nos enseñó a orar diciendo: "Venga a nosotros tu reino". (PREIN, 2008).

Más aún, la noción de reino de Dios posee una fuerte implicancia política, pero no en el sentido partidario sino militante. En una entrevista realizada también a Prein (ELIA, 2010), a la pregunta “¿Por qué a la iglesia evangélica le cuesta más introducirse en la política?”, éste responde:

\footnotetext{
Porque no entiende que significa "Mi reino no es de este mundo". Unos creen que es alejarse de todo lo "mundano". Los otros que creen estar superados, entran en la política de la misma manera que los políticos la desarrollan. Es vergonzoso. Tenemos una cultura diferente, la Cultura de Jesús y debemos esparcirla en todo ámbito en el que nos desarrollemos [...] Muchos quieren hacer política con los políticos y llegar a lugares encumbrados, y para ello usan a la Iglesia. Otros creemos que tenemos que andar con la gente defendiéndoles y preocupándonos por ellos. Gente y no cargos [...] En definitiva, la Iglesia no debe introducirse en la política, debemos estar al lado de la gente con todo lo que esto implica, atendiendo las necesidades de la gente, ya que esto es la prioridad uno para Dios y así debe ser para nosotros... Hablar menos, escuchar más y darnos por completo. (PREIN, 2010).
}

El concepto de reino de Dios, entonces, se relaciona con una tensión inherente en la identidad cristiana: por un lado, ella responde a una realidad que se espera "más allá" (tanto histórica como teológicamente), aunque, por otro lado, se vincula estrechamente con los avatares y dinámicas históricas de la cotidianeidad de los creyentes. Las dos citas de Prein nos permiten ver, por un lado, que el reino de Dios tiene directa relación con el contexto social y su transformación, y por otro, representa una condición disruptiva de la acción de la iglesia, que va más allá de las formas de institucionalidad y mecanismos de intervención social. Lo vemos en las palabras de Cesar, otro miembro del cuerpo pastoral, en una predicación dominical: "Nuestro pastor dice: estemos firmes 
para la guerra. Escuchemos su palabra [...] Como dice nuestro pastor: el reino de Dios está en nuestras actitudes”. (Claudio A., miembro de la iglesia). ${ }^{20}$

En resumen, la idea de reino de Dios como una realidad paradójica cuya condición es supra-histórica y a su vez inserta en la realidad, da cuenta de una ontología política propia en el pentecostalismo, donde la comunidad eclesial se comprende a sí misma en la frontera de una tensión entre una vivencia histórica concreta y la influencia en el contexto, siempre emergente en la experiencia de la espiritualidad. En otros términos, la tensión que efectiviza la presencia del reino promueve una visión dinámica de lo social, la cual siempre se encuentra abierta a la intervención de lo divino, especialmente de la mano de la comunidad creyente.

\subsection{Los "testimonios" como pedagogía política}

La práctica de los testimonios sobre experiencias personales es central tanto en los momentos de predicación como en las reuniones de planificación de área en el CCNV en particular como en todo el espectro evangélico. En una reflexión bíblica sobre la necesidad de defender políticas públicas que prioricen el desarrollo laboral, Guillermo Prein entrelaza el relato con la historia de un joven que en tiempos de crisis económica no tenía trabajo y se sentía desmotivado para estudiar, hasta que llegó a la iglesia y uno de sus líderes lo impulsó a que aprendiera pintura. "Dios hizo el milagro -afirmó Prein - y hoy es un artista que vive de su trabajo y realiza exposiciones en el exterior". (Guillermo Prein, pastor principal) ${ }^{21}$.

Otro ejemplo se vivió en una reunión de LATE, donde se organizaban actividades de sensibilización política. Al comenzar, el co-pastor que dirige la reunión pregunta a los presentes: “¿qué hizo Dios en mi vida y contexto?” (PANOTTO, 2020), como una manera de identificar algunos elementos experienciales que servirían de punto de inicio para los temas a abordar en las actividades que se planificaban. Esta centralidad en la experiencia personal nos

\footnotetext{
${ }^{20}$ Entrevista personal. Capital federal, marzo 2016.

${ }^{21}$ Observación de campo. Nota tomada de predicación en reunión semanal principal, domingo 9 de abril, 2017.
} 
permite visualizar el punto de partida de las dinámicas entre legitimación y ruptura que desarrollamos anteriormente.

En otras palabras, la radicalidad en la dimensión personal de la experiencia espiritual moviliza una comprensión de lo identitario que evoca la posibilidad de quiebre con el orden social y sus estructuras políticas, con los dogmas eclesiales y su clausura institucional, con segmentaciones teológicas "fundamentalistas" y circunstancias concretas (PANOTTO, 2014). El testimonio significa hablar de identidad como una diferencia constitutiva (CONNOLLY, 1991; HALL; DU GAY, 2011; HALL; DA SILVA; WOODWARD, 2000) donde el ser-ahí circunscrito en los avatares del contexto deviene posibilidad-de-ser por el actuar de Dios. Esto adquiere un fuerte cariz teológico dentro del pentecostalismo: nada me condena a la situación en que estoy, sino que todo es posible con la guía del Espíritu Santo y el actuar irruptor de Dios.

Aquí interviene también una idea muy presente tanto en el pentecostalismo como en otros grupos evangélicos: la idea de la singularidad a través del llamado o elección divina, las cuales se expresan en los testimonios como expresiones concretas y únicas de la intervención de Dios en la vida de individuos particulares. Dicha singularidad emerge, precisamente, de esa puesta en práctica o, mejor dicho, puesta en escena, donde el testimonio representa una narrativa que no sólo da cuenta de la manifestación histórica de Dios sino de una pedagogía a partir de la cual el sujeto se presenta, se interpreta y se "expone", inscribiéndose en un ejercicio hermenéutico donde incluye la comunidad.

En palabras de Foucault (2003), los testimonios evocan a una "tecnología del yo" que permite ver la dialéctica agencia-estructura desde el "conócete a ti mismo", a partir de lo cual se empodera a los creyentes a través de una relectura desde elementos teológicos (la fuerza del Espíritu), procesos de identificación con otros testimonios y la articulación con espacios alternativos de socialización (ALGRANTI, 2007). Aquí sirve también la distinción que propone Marramao (2014) entre la religión como identidad (en tanto proceso de "desidentificación" con diversas segmentaciones, donde se construye una identidad diferencial) y medio de identificación (donde entra el espacio comunitario como marco de 
asimilación). A su vez, la relación entre los relatos testimoniales, los discursos teológicos y las reflexiones sobre el contexto sociopolítico, conlleva un proceso de identificaciones múltiples (MAFFESOLI, 2005), donde los elementos estrictamente religiosos - sean discursivos como institucionales - actúan como instancias de desplazamiento y aprehensión de prácticas y discursos sociopolíticos, que se evidencian en opciones partidarias, construcción de imaginarios ideológicos, etc. (LAPLANTINE, 2007).

\subsection{Guerra espiritual y constitución de diferencias ontológicas}

Por último, el CCNV también responde a una cosmovisión particular sobre la acción del diablo, el mal y la intervención de los demonios, también llamada "guerra espiritual" (ALGRANTI, 2010, p. 191-199). Esta teología responde a una visión que sostiene que "detrás" de la realidad histórica intervienen fuerzas del bien (Dios) y del mal (Diablo), que condicionan de diversas maneras los avatares cotidianos de las personas. La iglesia y los creyentes poseen una sensibilidad particular sobre dicha disputa, lo que los ubica en un lugar de cierta negociación e intervención activa.

La práctica y la teología relacionadas con la demonología ha ido cambiando en las últimas décadas. El pentecostalismo, desde sus orígenes, ha dado gran importancia al tema de lo demonológico, lo que se evidencia en las recurrentes prácticas de exorcismo que se realizan no sólo en situaciones puntuales cuando es requerido por parte de algún miembro de la iglesia, sino de manera más "institucional”, es decir, como parte de la visión teológica presente en los momentos litúrgicos.

Por esta razón, la expulsión de demonios ya no se ubica solamente en una persona que da cuenta de una "manifestación demoníaca" sino que el tipo de exorcismo cobra un alcance mayor, donde se intenta expulsar todo tipo de espíritus que afecten a la comunidad en su conjunto - sea de manera personal o grupal - en distintas circunstancias. En Argentina, esta dinámica era común en las llamadas “campañas evangelísticas" de grandes tele-predicadores que llenaban estadios y hacían exorcismos masivos (WYNARCZYK, 2014). 
En la década de los '9o surge el llamado “mapeo espiritual” y con éste la denominada guerra espiritual (PRIEST et al, 1998). Esta perspectiva teológica nace en grupos neopentecostales norteamericanos, aunque pronto se extiende a nivel global. Dicha corriente plantea que existen "espíritus territoriales” que gestan diversos males a un nivel más bien nacional, regional y hasta continental. Existen, inclusive, mapas que nombran estos demonios. Este concepto redefine el concepto no sólo de las prácticas de exorcismo sino de las mismas comprensiones sobre el modo en que los demonios actúan: ellos no sólo afectan a individuos específicos, sino que se relacionan con "males" mayores, reflejados en problemáticas sociales, crecimiento de identidades religiosas que se creen dañinas (ej. Islam o los grupos afrodescendientes), inclusive en situaciones catastróficas, sean climáticas como políticas.

En las liturgias del CCNV existe una apelación al lugar de las fuerzas demoníacas, aunque no se apoya en la idea de guerra espiritual, al menos en su concepción tradicional. En todas las reuniones hay un momento especial de oración enfocado en este tema, donde se encuentran expresiones que se dirigen directamente a las fuerzas demoníacas -“demonio, te echamos fuera en el nombre de Jesús" - como otras frases más bien generales, que tratan de alcanzar a todo el grupo - "reprendemos todo espíritu de maldad, de daño, que pueda rondar entre quienes están aquí”. Una vez a la semana, se desarrolla lo que se denomina “culto de liberación”, el cual se asemeja a lo que es una reunión de oración por necesidades personales, pero donde se da mayor énfasis a la "reprensión” demoníaca, y en algunas ocasiones se realiza un exorcismo.

Lo que puede parecer un imaginario mágico - y por ende des-historizado y más relacionado con la presencia de fuerzas supra-naturales que con elementos cotidianos -, cobra otros matices cuando notamos ciertas divergencias que se dan en algunos momentos de "reprensión de demonios" dentro de los cultos del CCNV, donde las fuerzas demoníacas se nominan a través de la identificación de problemáticas cotidianas de los creyentes; es decir, se “expulsan” y "reprenden” espíritus de depresión, de culpa, de desánimo, de tristeza, entre otros. 
En una predicación, Prein afirma que "el diablo conoce nuestro idioma y nos habla en nuestro idioma", enfatizando en el hecho de que ciertas acciones que las personas realizan no parten de ellas sino del diablo que hace pensar "lo contrario". En esta misma predicación, Prein afirma que existen demonios detrás de los economistas del país, quienes constantemente promueven teorías falsas para desanimar a la sociedad. "iEsos son los espíritus que debemos reprender!" 22 , sentencia. Las fuerzas demoníacas, en este caso, se relacionan directamente con los avatares no solo cotidianos sino también sociopolíticos.

En la misma dirección de lo tratado en el punto anterior sobre el reino de Dios, la realidad demoníaca en la cosmovisión pentecostal imprime un abordaje conflictivo o disruptivo sobre lo social desde una clave "espiritual". El contexto se encuentra en un proceso constante de transformación en la medida de que este "enfrentamiento" se lleve a cabo. Pero ella tiene como epicentro la misma vivencia de los creyentes en su contexto específico, por lo cual hay un llamado a la intervención de los sujetos. Como asevera Cantón (2009), la lucha espiritual conlleva una dimensión práctica cuya apelación al "alejamiento del mundo" no envuelve una apatía sobre la realidad sino un distanciamiento de ciertos elementos sociales que provocan sufrimiento, para desde allí intervenir en la fuerza espiritual del bien.

En conclusión, el lugar de la confrontación con las fuerzas demoníacas adquiere un lugar más complejo si lo vemos como una ontología política. En este sentido, tal como ya hemos sugerido, la disputa entre el mundo espiritual y el mundo demoníaco representan dos ontologías en tensión dentro de un mismo marco histórico-cultural, que - reinterpretando lo abordado por Laclau imprime una "frontera interna" en la vivencia histórica del creyente y la iglesia, la cual sirve no sólo a una distinción de realidades sino también a la demarcación de un escenario de posibilidades de ser y de conflictividades, al ubicarse en una frontera que permite superar las consecuencias del mal y remitir a "lo espiritual" como un horizonte que deconstruye y resignifica los sentidos y vivencias concretas.

\footnotetext{
${ }^{22}$ Nota tomada de predicación en reunión semanal principal. Templo CCNV, Capital Federal, junio 2015
} 


\section{Conclusiones}

En el presente artículo hemos analizado el caso del CCNV como un espacio eclesial el cual resignifica su identidad pentecostal, no sólo como un marco de construcción identitaria desde una dimensión política, sino, más aún, desde una dinámica disruptiva y crítica, desde una visión teológica y religiosa como también ideológica. En este sentido, lo que intentamos demostrar fueron dos cosas. Primero, que todos los elementos constitutivos de una identificación religiosa sirven como marcos para producir y resignificar imaginarios y prácticas sociopolíticas, no necesariamente desde una "conciencia ideológica" particular sino desde los desplazamientos que producen las propias dinámicas constitutivas de cada elemento. Y segundo, que "lo pentecostal" dista de contener un tipo específico de identificación ideológica o política. Más bien, se trata de un conjunto de especificidades identitarias dentro del campo evangélico, que pueden vehiculizar todo tipo de prácticas y asunciones ideológicas. En otros términos, asumir una identidad es, a la vez, ubicarse en un marco de reapropiaciones diversas.

En este sentido, si lo pentecostal posee alguna dimensión política particular, es por su especificidad disruptiva como configuración identitaria. Esto en lo que refiere al carisma que promueve - donde la experiencia de fe y el actuar de Dios se presentan siempre como instancias de cambio, transformación y disputa -, el tipo de antropología - donde el creyente es empoderado como un sujeto que reinterpreta, que actúa, que siente, que se moviliza, que tiene poder y los procesos de institucionalización, que imprimen una dinámica que desafía las comprensiones tradicionales en el campo evangélico. Todo esto se articula más eficientemente con un conjunto de demandas en el espacio social, tal como la necesidad de una compresión más integral de las personas, un abordaje afectivo de las relaciones y lo político, y una focalización en las demandas antes que en banderas ideológicas particulares.

Hemos analizado algunas prácticas y retóricas dentro del CCNV, las cuales reflejan esta “doble vía” de la identificación religiosa: por un lado, un posicionamiento identitario religioso específico, y por otro, una diversidad de identificaciones que puede provocar en términos sociopolíticos, según el marco 
en que se los inscriba: posiciones ideológicas y subjetivas, demarcaciones con otros discursos e instituciones, historias, imaginarios, entre otros. Por ello hablamos de una personalización religiosa como identificación disruptiva. De alguna manera, ello tiene que ver con un estatus constitutivo del pentecostalismo, el cual se ubica como un dispositivo deconstructor de prácticas, discursos e imaginarios hegemónicos sobre lo evangélico, lo religioso y lo sociopolítico.

Por todo esto, los elementos constitutivos de la pentecostalidad en tanto reservorio simbólico y ritual -desde las nociones de la presencia del Espíritu, el carisma del liderazgo, las experiencias personales de fe, los procesos hermenéuticos en torno a la lectura del texto bíblico, la apelación a los testimonios, el abordaje de los sufrimientos, entre otros -, no solo marcan una frontera interna con el campo evangélico, sino que reaccionan frente al conjunto de matrices e imaginarios sociopolíticos, hegemónicas y hereditarias de cierto proceso de modernización.

\section{REFERENCIAS}

ALEMÁN, J. En la frontera: sujeto y capitalismo. Buenos Aires: Gedisa, 2014.

ALGRANTI, J. Auge, decadencia y 'espectralidad' del paradigma modernizador: viejos y nuevos problemas en el estudio del pentecostalismo en América Latina. In: STEIL, C; MARTÍN, E.; CARMUCA, M. Religiones y culturas: perspectivas latinoamericanas. Buenos Aires: Biblos, 2009. p. 57-87.

ALGRANTI, J. La política en los márgenes: estudio sobre los espacios de participación social en el neo-pentecostalismo. Caminhos, Goiás, v. 5, n. 2, p. 361-380, 2007.

ALGRANTI, J. Política y religión en los márgenes. Buenos Aires: Ediciones Ciccus, 2010.

ARDITI, B. La política en los bordes del liberalismo: diferencia, populismo, revolución, emancipación. Barcelona: Gedisa Editorial, 2011.

ASAD, T. Formations of the secular: Christianity, Islam and Modernity. Calofornia: Stanford University Press, 2003.

BOURDIEU, P. ¿Qué significa hablar? Economía de los intercambios linguísticos. Madrid: Editora Nacional, 2002.

CANTÓN, M. Simbólica y política del diablo pentecostal. Revista Cultura y

Religión, Chile, v. 1, n. 11, p. 81-94, 2009. 
CARBONELLI, M. Desde el barrio: perspectivas acerca de la actividad política de pastores evangélicos en el Conurbano Bonaerense. Ciencias Sociales y Religión, Campinas, v. 1, n. 11, p. 107-129, 2009.

CONNOLLY, W. Identity/difference: democratic negotiations of political paradox. Ithaca: Cornell University Press, 1991.

DA SILVA, T.; HALL, S.; WOODWARD, K. (org.). Identidade e diferença: a perspectiva dos estudos culturais. Petrópolis: Vozes, 2000.

ELIA, D. Guillermo Prein: la Iglesia no entiende que significa 'Mi reino no es de este mundo', 2010. Disponible en: http://www.boomker.com/guillermo-prein-la-iglesiano-entiende-que-significa-mi-reino-no-es-de-este-mundo. Consultado el: 26 nov. 2020.

FALCO, R. Charisma and myth. Londres: Continuun, 2010.

FOUCAULT, M. La hermenéutica del sujeto. Buenos Aires: FCE, 2002.

FOUCAULT, M. Tecnologías del yo. Madrid: Editora Nacional, 2003.

GIDDENS, A. Modernidad e identidad del yo: el yo y la sociedad en la época contemporánea. Barcelona: Ediciones Península, 1991.

HALL, S.; DU GAY, P. Comp. Cuestiones de identidad cultural. Amorrortu Editores: Buenos Aires, 2011.

KETZER, D. Ritual, politics, and power. New Heaven: Yale University Press, 1988.

LACLAU, E. Emancipación y diferencia. Buenos Aires: Ariel, 1996.

LACLAU, E. La razón populista. Buenos Aires: FCE, 2005.

LAPLANTINE, F. El sujeto, ensayo de antropología política. Barcelona: Edicions Bellaterra, 2007.

LÓPEZ, D. Pentecostalismo y transformación social. Buenos Aires: FTL/Kairós, 2000.

MAFFESOLI, M. La transfiguración de lo político. Barcelona: Herder, 2005.

MARRAMAO, G. El reencantamiento del mundo en la era global. Religión e identidad. En: GAMPER, D. (ed.). La fe en la ciudad secular. Laicidad y democracia. Madrid: Trotta, 2014. p. 41-55.

MÍGUEZ, D. La conversión religiosa como estrategia de supervivencia. Los pentecostales y el descenso social durante la "década perdida". Intersecciones en Antropología, Buenos Aires, n. 2, p. 73-88, 2001.

MOUFFE, C. En torno a lo político. Buenos Aires: FCE, 2009.

MOULIÁN TESMER, R. El sello del Espíritu derramado sobre la carne. Santiago: Ediciones Kultrún, 2017. 
PANOTTO, N. Fe que hace la diferencia: prácticas religiosas, ontología(s) y construcción de lo público. Un caso dentro del pentecostalismo argentino. Liminales. Escritos sobre psicología y sociedad, Chile, v. 1, n. 10, p. 29-45, nov. 2016.

PANOTTO, N. Liderazgo, carisma y procesos de identificación en el campo evangélico. El caso de una iglesia pentecostal en Argentina. Revista Brasileira de História das Religiões, ANPUH, ano XIII, n. 37, p. 219-251, 2020.

PANOTTO, N. Pentecostalismos y construcción de identidades sociopolíticas.

Desafíos, Colombia, v. 26, n. 2, p. 73-96, 2014.

PANOTTO, N. Religión y nuevas formas de militancia: pentecostalismo y política en Capital Federal. Revista Proyecto, año 24, n. 61-62, p. 203-221, 2013.

PREIN, G. Pentecostal-es. 2008. Disponible en: https://guillermoprein.wordpress.com/2008/06/26/pentecostal-es/. Consultado el: 26 noviembre 2020.

PREIN, G. Por una Patria de iguales. 2012. Disponible en: http://www.guillermoprein.com/2012/o9/por-una-patria-de-iguales.html. Consultado el: 31 mayo 2020.

PREIN, G. Se cumple hoy como ayer. 2013. Disponible en: (http://www.guillermoprein.com/2013/o4/se-cumple-hoy-como-ayer.html. Consultado el: 30 mayo 2013.

PREIN, Guillermo. Mensaje personal recebida por < nicaloaspanotto@gmail.com> en 17 de octubre de 2016.

PRIEST, R. et al. Poder y misión: debate sobre la guerra espiritual en América Latina. San José: IINDEF, 1998.

SEMÁN, P. La recepción popular de la teología de la prosperidad. Scripta Ethnologica, v. XXIII, p. 145-162, 2001.

STARVAKAKIS, Y. La izquierda lacaniana: psicoanálisis, teoría, poítica. Buenos Aires: FCE, 2010.

STARVAKAKIS, Y. Lacan y lo político. Buenos Aires: Prometeo, 2007.

WYNARCZYK, H. Ciudadanos de dos mundos: el movimiento evangélico en la vida pública argentina 1980-2001. Buenos Aires: UNSAM Edita, 2009.

WYNARCZYK, H. Tres evangelistas carismáticos: Omar Cabrera, Héctor Aníbal Giménez y Carlos Annacondia. Ciudad Autónoma de Buenos Aires: Diversa, 2014. 